\title{
On the Driving Mechanism of the Annual Cycle of the Florida Current Transport
}

\author{
LARS CZESCHEL AND CARSTEN EDEN \\ KlimaCampus, Institut für Meereskunde, University of Hamburg, Hamburg, Germany \\ RICHARD J. GREATBATCH \\ IFM-GEOMAR, Kiel, Germany
}

(Manuscript received 10 June 2011, in final form 16 December 2011)

\begin{abstract}
The mechanisms involved in setting the annual cycle of the Florida Current transport are revisited using an adjoint model approach. Adjoint sensitivities of the Florida Current transport to wind stress reproduce a realistic seasonal cycle with an amplitude of $\sim 1.2 \mathrm{~Sv}\left(1 \mathrm{~Sv} \equiv 10^{6} \mathrm{~m}^{3} \mathrm{~s}^{-1}\right)$. The annual cycle is predominantly determined by wind stress forcing and related coastal upwelling (downwelling) north of the Florida Strait along the shelf off the North American coast. Fast barotropic waves propagate these anomalies southward and reach the Florida Strait within a month, causing an amplitude of $\sim 1$ Sv. Long baroclinic planetary Rossby waves originating from the interior are responsible for an amplitude of $\sim 0.8 \mathrm{~Sv}$ but have a different phase. The sensitivities corresponding to the first baroclinic mode propagate westward and are highly influenced by topography. Considerable sensitivities are only found west of the Mid-Atlantic Ridge, with maximum values at the western shelf edge. The second baroclinic mode also has an impact on the Florida Current variability, but only when a mean flow is present. A second-mode wave train propagates southwestward from the ocean bottom on the western side of the Mid-Atlantic Ridge between $\sim 36^{\circ}$ and $46^{\circ} \mathrm{N}$ and at Flemish Cap, where the mean flow interacts with topography, to the surface. Other processes such as baroclinic waves along the shelf and local forcing within the Florida Strait are of minor importance.
\end{abstract}

\section{Introduction}

The Florida Current combines the western boundary component of the thermohaline and wind-driven circulations (Schmitz and Richardson 1991; Schmitz et al. 1992), and its volume transport, which is defined here as the transport between Florida and Grand Bahama, is one of the best known integral quantities measured in the world's ocean: Submarine cable measurements over more than $20 \mathrm{yr}$ reveal a mean transport of $32.3 \mathrm{~Sv}$ $\left(1 \mathrm{~Sv} \equiv 10^{6} \mathrm{~m}^{3} \mathrm{~s}^{-1}\right)$ (Larsen 1992). Figure 1 shows the monthly-mean seasonal cycle as measured by the telephone cable. We computed the monthly means from a time series of daily averages between April 1982 and September 2009 (taken from http://www.aoml.noaa.gov/ phod/floridacurrent/). The annual cycle is characterized by a maximum in July, minimum values from November to January, and an amplitude of $\sim 1.2 \mathrm{~Sv}$. The annual

Corresponding author address: Lars Czeschel, Institut für Meereskunde, Bundesstrasse 53, 20146 Hamburg, Germany.

E-mail: lars.czeschel@zmaw.de cycle is not stable over the whole time series and the amplitude varies in different time periods (Baringer and Larsen 2001), with maximum values of $\sim 2.5 \mathrm{~Sv}$ in the period 1982-90. The standard deviation of the individual monthly-mean transport anomalies is $2.4 \mathrm{~Sv}$. It should be noted that there is significant transport variability on time scales shorter than the annual signal (Larsen 1992; Meinen et al. 2010).

In addition to the Florida Current, the western boundary current system also contains currents east of the Bahamas: the northward-flowing shallow Antilles Current and the southward-flowing deep western boundary current. Observations reveal a mean transport of $\sim 6 \mathrm{~Sv}$ (Lee et al. 1996; Johns et al. 2008) for the Antilles Current and of $\sim 26 \mathrm{~Sv}$ for the southward-flowing deep western boundary current (Bryden et al. 2005; Johns et al. 2008). All observational estimates report extremely large transport fluctuations indicating rich eddy activity. For example, in a one-year time series, Johns et al. (2008) found fluctuations from -15 to $25 \mathrm{~Sv}$ in the Antilles Current and from -60 to $3 \mathrm{~Sv}$ in the deep western boundary current (negative values denote transport to 




FIG. 1. Annual cycle of the Florida Current transport (Sv) as measured by the voltage induced in the telephone cable. The annual cycle is calculated using monthly-mean data from April 1982 to September 2009. The gray shaded area marks the Florida Current transport variability by the standard deviation of each individual month.

the south). These fluctuations may be caused by strong mesoscale eddy activity but may also include fluctuations of the ocean interior Sverdrup response, as suggested by Lee et al. (1996) and Johns et al. (2008).

Niiler and Richardson (1973) noticed that flat-bottom Sverdrup theory does not hold for the seasonal variation of the Florida Current because the observed transport has lower amplitude and a phase shift with a summer rather than a winter maximum. Gill and Niller (1973) point out the importance of variable bottom topography for the annual cycle of the Florida Current. The response of a wind-driven stratified ocean is initially strongly modified by variable topography, and it is only when most baroclinic Rossby waves emitted from the wind forcing have reached the western boundary that flat-bottom Sverdrup balance tends to be reached (Anderson and Killworth 1977). Anderson and Corry (1985a) show that transport variation can be related to barotropic Rossby waves generated by wind stress and wind stress curls acting over variable bottom topography. In addition, baroclinic Kelvin waves from the north also induce transport variations. In a subsequent paper, Anderson and Corry (1985b) simulated the Florida Current seasonal cycle in agreement with observation using a realistic wind stress climatology. Experiments where the wind forcing was restricted regionally identified the Caribbean and the western Atlantic north of the Florida Strait as important regions. The subpolar North Atlantic was not part of the model domain of Anderson and Corry (1985b), but wind stresses therein are able to influence the Florida Current transport as well (Greatbatch and
Goulding 1989). These model studies also show that the annual cycle can be roughly captured by a barotropic model (Greatbatch et al. 1995). Using different wind stress climatologies in an eddy-permitting model, Böning et al. (1991) point out the importance of the particular data product used to force the model, whereas model parameters such as dissipation seem to play a smaller role for the annual cycle.

In the present study, the mechanisms that determine the Florida Current transport on annual time scales are revisited using an adjoint model approach, with the advantage that we are able to identify key regions for the forcing in a clear chronological order: that is, the time lags of the response from each individual forcing region. Section 2 presents details of the model setups and the adjoint approach. In section 3, we present the results for the flat-bottom case, the impact of variable topography, and the chosen model parameters, whereas the conclusions are summarized and discussed in section 4 .

\section{The model}

The model used in this study is the Massachusetts Institute of Technology (MIT) general circulation model (Marshall et al. 1997) and its adjoint (Marotzke et al. 1999). For the adjoint, we use two different configurations: first, a global model with a horizontal resolution of $1^{\circ}$ and 33 layers in the vertical. A detailed description of this setup is given in Czeschel et al. (2010). Additionally, we use a regional model of the North Atlantic ranging from $18^{\circ} \mathrm{S}$ to $72^{\circ} \mathrm{N}$. Here, the resolution is increased to $1 / 6^{\circ}$ in the horizontal and to 45 vertical levels.

A summary of the adjoint model experiments is given in Table 1. Most of the experiments use an adjoint for a model linearized about a state of rest, either unstratified or using a horizontally uniform stratification. In a further experiment, we use the adjoint of the coarse model linearized about a realistic state featuring a circulation as simulated after an 80-yr-long spinup integration of the forward model. The realistic coarse-resolution forward model is described in detail in Czeschel et al. (2010). Note that a basic state with flow can only be used in a non-eddy-permitting model, such as the coarse model of Czeschel et al. (2010), to avoid strongly nonlinear dynamics related to mesoscale eddy activity restricting the applicability of adjoint methods (see, e.g., Köhl and Willebrand 2002, and references therein). However, nonlinear processes emerge rather fast even in the high-resolution case with a basic state at rest, allowing only an integration of 3 months back in time. In contrast, the low-resolution model holds linearity several years (Czeschel et al. 2010). The horizontally uniform stratification is obtained from annual-mean climatological data 
TABLE 1. List of adjoint experiments. The horizontal uniform stratification $N(z)$ is based on Levitus and Boyer (1994) climatology.

\begin{tabular}{lclll}
\hline \multicolumn{1}{c}{ Expt } & Resolution & Ocean status & \multicolumn{1}{c}{ Stratification } & Topography \\
\hline Coarse & $1^{\circ}$ & After 80 yr spinup & Varying & $\begin{array}{c}\text { 5-minute gridded elevations/bathymetry } \\
\text { for the world (ETOPO5) } \\
\text { Coarse_bclin }\end{array}$ \\
Coarse_btrop & $1^{\circ}$ & At rest & Horizontal uniform & ETOPO5 \\
Coarse_bclin_flat & $1^{\circ}$ & At rest & Unstratified & ETOPO5 \\
High_bclin & $1^{\circ}$ & At rest & Horizontal uniform & Flat bottom \\
\hline
\end{tabular}

(Levitus and Boyer 1994). The initial profile is calculated by averaging temperature and salinity values in each vertical layer of the North Atlantic. The exception is experiment Coarse, which is linearized about a model realization from a forward integration using the model setup described in Czeschel et al. (2010) and includes the full three-dimensional flow.

The equations are discretized on a $\mathrm{C}$ grid, where the horizontal velocity components are staggered in space; hence, formulation of the Coriolis term involves spatial averaging. When the deformation radius is not resolved, as in our $1^{\circ}$ model, this spatial averaging allows gridscale noise to persist. Adcroft et al. (1999) introduced the $\mathrm{C}-\mathrm{D}$ scheme to overcome this problem and we applied the scheme in our $1^{\circ}$ model, an issue that is discussed below.

Conventional model sensitivity studies involve perturbing individual control variables (initial conditions, forcing, model parameters) so that, to assess the sensitivity to all control variables at all times, a huge number of experiments is necessary. In contrast, the present model allows an adjoint calculation that gives the linear sensitivity of a cost function to all the control variables in a single integration, at all times between the time of the cost function evaluation and the time of the initial conditions. The adjoint is constructed by automatic differentiation (Giering and Kaminski 2003); the cost function can be any scalar function of the model output, as long as it remains differentiable with respect to the control variables. The adjoint approach provides the sensitivity to small-amplitude perturbations about a linearization of the underlying model.

The cost function used in this study is defined as the monthly-mean Florida Current transport at $26.5^{\circ} \mathrm{N}$ between the Bahamas and Florida. The $1^{\circ}$ model does not resolve the Bahamas islands, and we choose as Florida Current transport the transport at $25^{\circ} \mathrm{N}$ between Florida $\left(80^{\circ} \mathrm{W}\right)$ and $77^{\circ} \mathrm{W}$. The chosen offshore limit is based on an analysis of the fully forced forward model, which makes sure that all the transport through the Caribbean Sea is captured. The mean transport between Florida $\left(80^{\circ} \mathrm{W}\right)$ and $77^{\circ} \mathrm{W}$ at $25^{\circ} \mathrm{N}$ is $\sim 38 \mathrm{~Sv}$ and has an annual cycle with an amplitude of $\sim 1.2 \mathrm{~Sv}$. The transport through the Caribbean Sea is $\sim 37.5 \mathrm{~Sv}$. Although a clear distinction between Florida Current and Antilles Current is not possible in our $1^{\circ}$ model, the northward transport in the top $1000 \mathrm{~m}$ increases farther offshore, reaching a maximum transport of $\sim 45 \mathrm{~Sv}$ mostly due to recirculation (see Fig. 9 for the horizontal circulation). Below $1000 \mathrm{~m}$, the transport is southward as part of the deep western boundary current. Note, however, that the "model Antilles Current" and the deep western boundary current are not part of our cost function.

Because the first month of the adjoint calculation contains the evaluation of the cost function (i.e., the monthly-mean Florida Current transport), it is referred as the "zeroth month" or the month during cost function evaluation. The second month is referred as the first month prior to cost function evaluation and so on. Throughout the paper, we analyze time-dependent monthly-mean sensitivities. For example, if we assume that the cost function is a December mean, then the sensitivity to zonal wind stress in the second month prior to cost function evaluation refers to the impact of a monthlymean zonal wind stress applied in October.

\section{Results}

\section{a. Flat-bottom ocean}

Gill and Niller (1973) point out the importance of variable bottom topography for the annual cycle of the Florida Current. Flat-bottom Sverdrup theory is unlikely to hold on seasonal time scales. For periods much less than the time taken for the wind-generated baroclinic Rossby waves to propagate from their point of origin to the location in question, the ocean response is primarily that for a homogenous ocean and thus strongly modified by topography (Anderson and Corry 1985a). However, we start the discussion with a model configuration with a flat bottom because we expect in a flatbottom ocean model that the annual cycle of the Florida Current is in approximate agreement with simple Sverdrup theory. The flat-bottom case gives us therefore the possibility to test our adjoint model and start the discussion. 

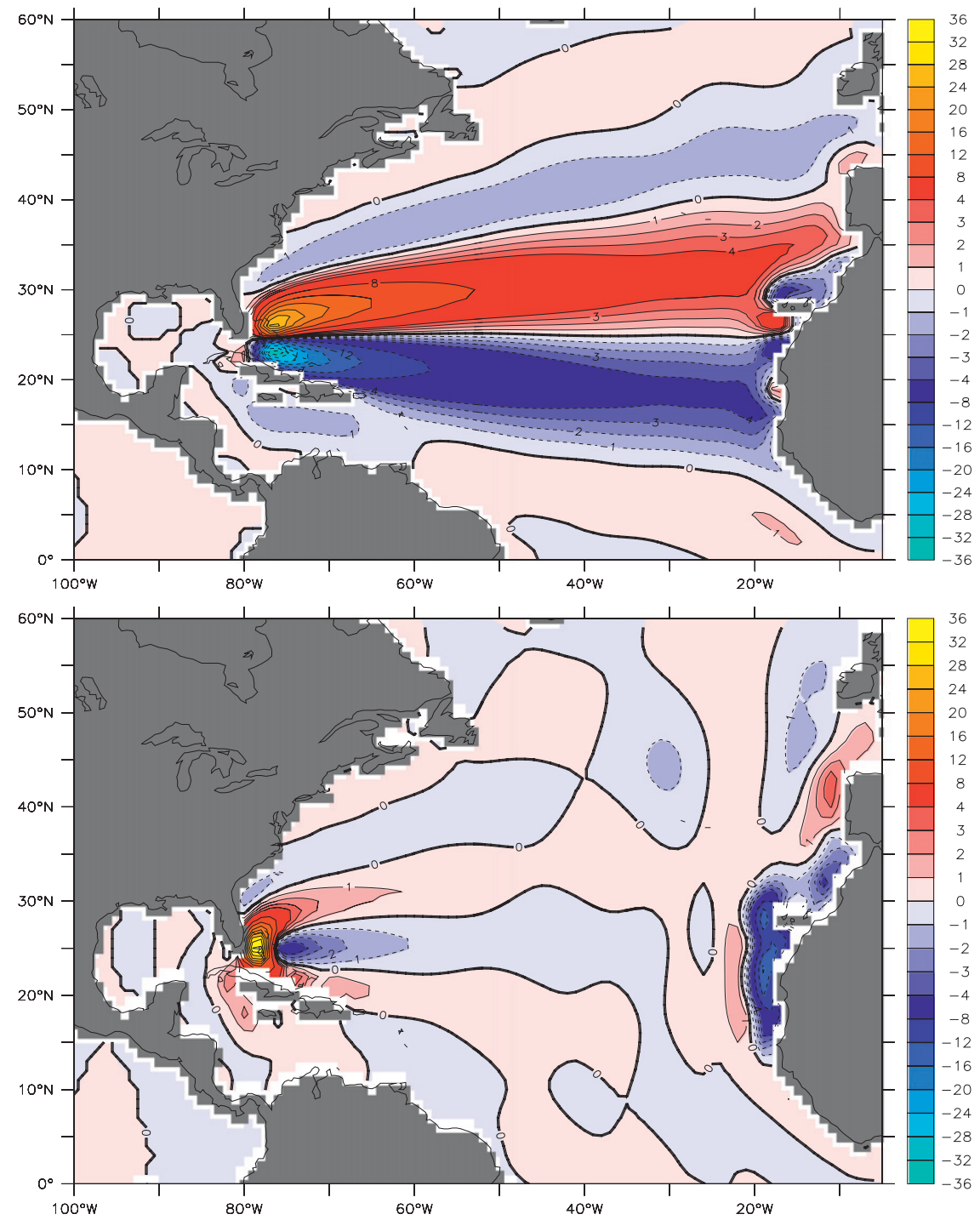

FIG. 2. Sensitivity of the Florida Current transport to (top) zonal and (bottom) meridional wind stress from the zeroth month within the cost function evaluation of experiment Coarse bclin_flat. Units are $10^{-11} \mathrm{~Sv}\left(\mathrm{~N} \mathrm{~m}^{-2}\right)^{-1}$.

In Coarse_bclin_flat, we use the $1^{\circ}$ model with a realistic land mask but with a uniform ocean depth of $3500 \mathrm{~m}$ (the results are not sensitive to the exact choice of depth as long as the bottom is placed well below the thermocline). Note that the adjoint model is linearized about a model that is unforced and at rest but is horizontally uniformly stratified. The effect of a realistic circulation including a background flow will be discussed in the next section. Figure 2 shows the sensitivity of the monthly averaged Florida Current to zonal and meridional wind stress in the zeroth month during cost function evaluation. (Note that because no seasonal cycle is present in the basic state each individual month is the same: i.e., there is no seasonal cycle in the sensitivities).
In general, the sensitivities to zonal wind stress are higher than to meridional wind stresses, especially in the interior. According to flat-bottom Sverdrup theory, the vertically integrated meridional transport $V$ is given by

$$
V=\frac{1}{\beta} \mathbf{k} \cdot \nabla \times \boldsymbol{\tau},
$$

where $\tau$ is the wind stress and $\beta=\partial f / \partial y$ is the meridional gradient of the Coriolis parameter $f$. A positive zonal wind stress gradient as seen in Fig. 2 (top) at $25^{\circ} \mathrm{N}$ would force a southward Sverdrup transport in the interior along the same latitude. This flow would be compensated by a northward-flowing Florida Current transport, 
where different dynamics than given by Eq. (1) hold. The adjustment to wind stress by barotropic waves is very fast, allowing a rapid communication between the interior/eastern boundary with the western boundary (i.e., the Florida Current). Sensitivities from previous months are therefore negligible in Coarse_bclin_flat. Flat-bottom Sverdrup dynamics alone would result in a uniform sensitivity to wind stress curl anywhere along the section. However some additional processes modify this picture. Higher sensitivities are found in the western part of the subtropical gyre just east of the area where we defined the cost function. Local zonal wind stresses in the direction as suggested by the sensitivity pattern would force an Ekman convergence and a corresponding positive sea level height anomaly at $\sim 25^{\circ} \mathrm{N}, 75^{\circ} \mathrm{W}$. The resulting geostrophic velocities would be northward in the Florida Strait and southward in the interior leading to an increased Florida Current transport. A second band of much smaller negative zonal wind stress sensitivities show up from $\sim 30^{\circ} \mathrm{N}, 80^{\circ} \mathrm{W}$ to $\sim 45^{\circ} \mathrm{N}$, $10^{\circ} \mathrm{W}$, just north of the band of positive sensitivities. The suggested wind stress curl would result in a negative sea surface height (SSH) anomaly. Rossby waves and coastal Kelvin waves propagate this signal toward the western boundary at $\sim 25^{\circ} \mathrm{N}$, which would increase the Florida Current transport. Another process that is not part of the Sverdrup theory is that the waves are modified by viscous damping and the applied bottom friction in our model. Both contribute to the generally smaller sensitivities toward the east.

The sensitivity to meridional wind stress is concentrated around $25^{\circ} \mathrm{N}$ along the western and eastern boundaries (Fig. 2, bottom). The pattern is very similar to the sensitivity of the Florida Current to sea surface height (not shown). If we assume a meridional wind stress would act as the sensitivity pattern suggests [positive (negative) sensitivities means wind stress from south to north (north to south)], offshore Ekman transports would lower the sea level at the western and eastern boundaries and raise the sea level at $\sim 75^{\circ} \mathrm{W}$. The corresponding geostrophic velocities would be a southward flow in the interior and a northward-flowing Florida Current. Beside barotropic Rossby waves there is another route for the rapid communication from the eastern to the western boundary, which is through coastal Kelvin waves. Some evidence is given by the increased sensitivities at the eastern boundary north of $25^{\circ} \mathrm{N}$. Note that the sensitivities to wind stress are very similar in a model run without stratification as long as we consider the flatbottom case (not shown).

If we multiply the adjoint sensitivities by the pattern of realistic wind stress anomalies, we are able to model the Florida Current seasonal cycle "offline." Here, we

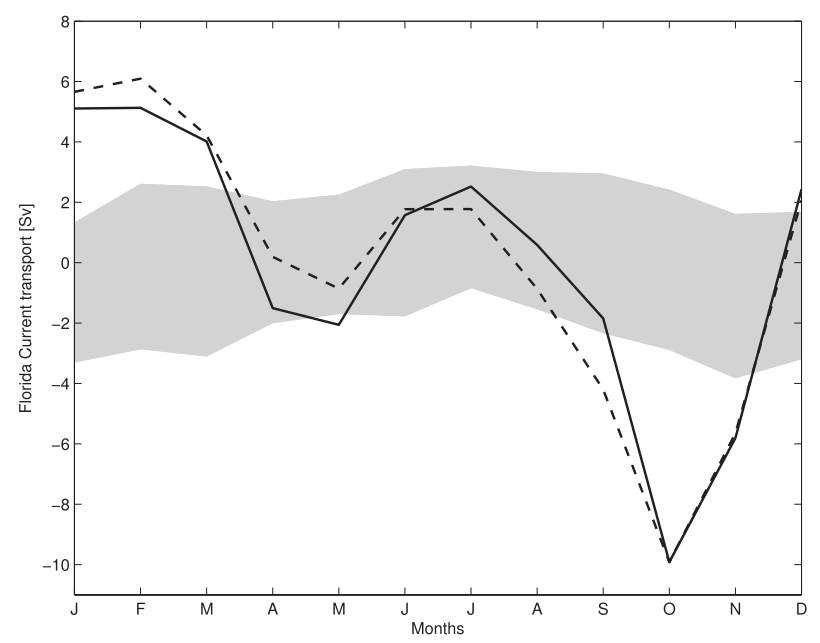

FIG. 3. Annual cycle of the Florida Current transport (Sv) derived from adjoint sensitivities of experiment Coarse_bclin_flat (dashed line) and from Sverdrup transport (solid line). For comparison, the gray shaded area marks the variability of the observations as in Fig. 1.

use the monthly-mean wind stress climatology from the National Centers for Environmental PredictionNational Center for Atmospheric Research (NCEPNCAR) reanalysis (Kalnay et al. 1996) so that our Florida Current (FC) transport anomalies $\Delta V_{\mathrm{FC}}$ are given by

$\Delta V_{\mathrm{FC}}=\int_{100^{\circ} \mathrm{W}}^{10^{\circ} \mathrm{E}} \int_{18^{\circ} \mathrm{S}}^{70^{\circ} \mathrm{N}} \frac{\partial V_{\mathrm{FC}}}{\partial \tau_{x}} \Delta \tau_{x}+\frac{\partial V_{\mathrm{FC}}}{\partial \tau_{y}} \Delta \tau_{y} d y d x$,

where $\Delta \boldsymbol{\tau}_{x}$ and $\Delta \boldsymbol{\tau}_{y}$ are the NCEP-NCAR zonal and meridional wind stress anomalies, respectively, and $\partial V_{\mathrm{FC}} / \partial \tau_{x}$ and $\partial V_{\mathrm{FC}} / \partial \tau_{y}$ are the adjoint sensitivities of the Florida Current transport to zonal and meridional wind stress, respectively. Figure 3 shows that the prediction of the adjoint model nearly matches the Sverdrup solution given by

$$
\Delta V_{\mathrm{FC}}=\int_{76^{\circ} \mathrm{W}}^{\text {Eastern Boundary }} \frac{1}{\beta} \mathbf{k} \cdot \nabla \times \Delta \boldsymbol{\tau} d x .
$$

The annual cycle has a maximum in winter and an amplitude of $\sim 8 \mathrm{~Sv}$. Note that the amplitude is rather low compared to other wind stress climatologies: for example, Barnier et al. (1995) reveal an amplitude of $\sim 12$ Sv and Hellerman and Rosenstein (1983) reveal an amplitude of $\sim 12 \mathrm{~Sv}$. However, it is well known that the observed Florida Current annual cycle has a lower amplitude and an out-of-phase shift toward summer (see Fig. 1; the variability of Florida Current observations by means of the standard deviation is also included in Fig. 3) so that the results are not in agreement with 

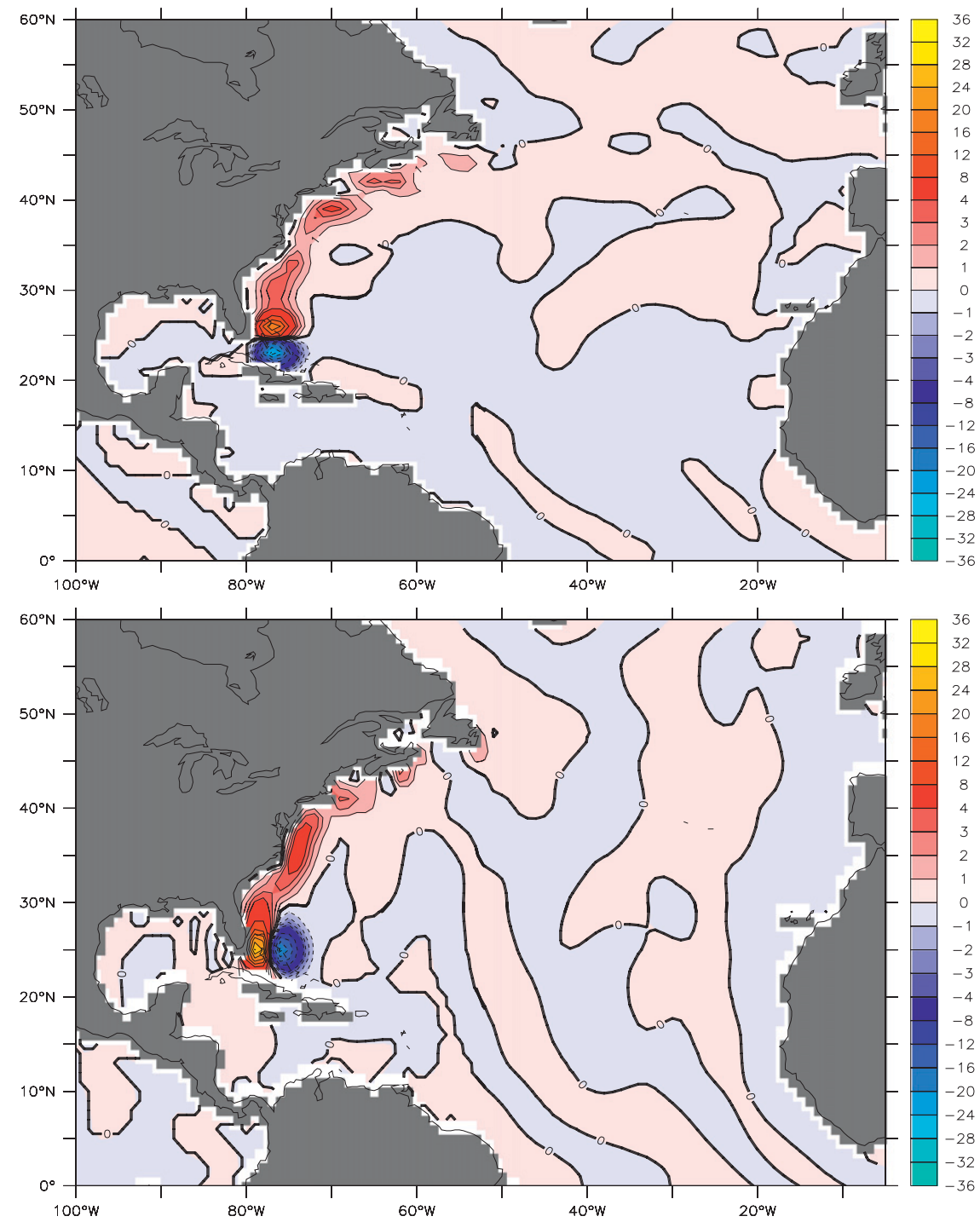

FIG. 4. Sensitivity of the Florida Current transport to (top) zonal and (bottom) meridional wind stress from the zeroth month within the cost function evaluation of experiment Coarse bclin. Units are $10^{-11} \mathrm{~Sv}\left(\mathrm{~N} \mathrm{~m}^{-2}\right)^{-1}$.

observations as is well known from previous studies (e.g., Niiler and Richardson 1973; Larsen 1992). On the other hand, the good agreement between model and theory in the flat-bottom case gives us confidence in our adjoint approach. The differences in both curves are mainly due to non-Sverdrupian dynamics such as local processes (see discussion of Fig. 2).

\section{b. Impact of topography and background flow}

Figure 4 shows the sensitivity of the Florida Current transport to zonal and meridional wind stress as in Fig. 2 for the zeroth month during evaluation in Coarse_bclin: that is, with the effect of variable bottom topography included. Both zonal and meridional wind stress sensitivities show a dipole structure at $\sim 25^{\circ} \mathrm{N}, 77^{\circ} \mathrm{W}$, which would lower (raise) the sea level in case of Ekman divergence (convergence) and hence alter locally the geostrophic transport of the Florida Current. This local Ekman pumping sensitivity is similar to that in Coarse bclin_flat (Fig. 2).

However, the nonlocal sensitivities are in general smaller compared to Coarse_bclin_flat and concentrated north of the Florida Strait and along the shelf off the U.S. coast in the subtropical gyre. The positive sensitivities along the coast are related to offshore Ekman transports (i.e., westward wind stress in the zonal direction and northward wind stress in the meridional direction), which lower the sea level at the 


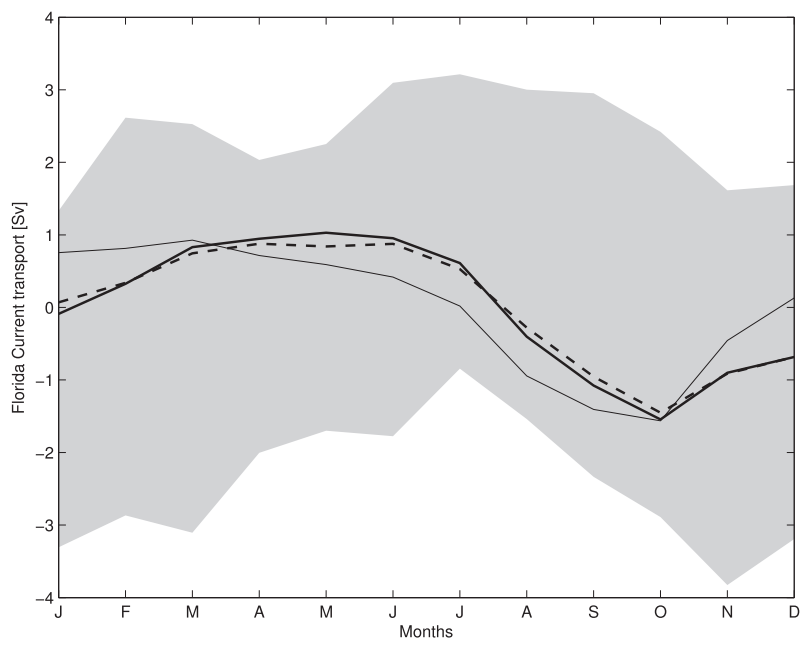

FIG. 5. Annual cycle of the Florida Current transport (Sv) derived from adjoint sensitivities to wind stresses in experiment Coarse (solid thick line) and experiment Coarse_bclin where the basic state is at rest (thin line). In both cases, the sensitivities of the last $3 \mathrm{yr}$ (0th-35th month) prior to cost function evaluation are considered. For comparison, the annual cycle of the full nonlinear forward run in experiment Coarse (dashed line) is also shown.

coast. These signals then propagate southward as coastally trapped or fast barotropic topographic Rossby waves enhancing the Florida Current transport at $25^{\circ} \mathrm{N}$. A rapid compensation of the interior southward Sverdrup transport as in Coarse_bclin_flat is missing. Such a compensation might take place farther offshore in the Antilles Current/deep western boundary current as suggested by Lee et al. (1996) and Johns et al. (2008).

In contrast to the flat-bottom case, contributions from earlier than the zeroth month cannot be ignored in a baroclinic model with topography (an issue that will be discussed later). Figure 5 shows the annual cycle of the Florida Current transport of the full nonlinear forward model as used in Czeschel et al. (2010) compared to the annual cycle calculated from adjoint sensitivities of Coarse as in Fig. 3 but with contributions from the 3-yr period (0th-35th month) before cost function evaluation. Note that Coarse is driven by realistic wind stress and buoyancy fluxes and is linearized about the full three-dimensional flow of the forward run (for details, see Czeschel et al. 2010). The very good agreement between both curves suggests that the sensitivity to wind stress of the last $3 \mathrm{yr}$ is nearly able to predict the whole annual cycle of the Florida Current. Buoyancy forcing, nonlinearities, and wind stress forcing earlier than $3 \mathrm{yr}$ before cost function evaluation seem to play a minor role. Note, that we compute the adjoint sensitivities from a monthly-mean cost function: that is, the Florida Current transport. As we started our adjoint backward calculation at the end of a model year the cost function is a December mean. To diagnose a correct annual cycle, we need actually 12 adjoint calculations starting every month during a year. However, in Fig. 5, we did the backward calculation only once, which is equivalent with the assumption that the annual cycle in the background flow is of minor importance for the annual cycle of the Florida Current.

Figure 5 additionally shows the annual cycle of Coarse compared to Coarse_bclin where the basic state is at rest. Both have a very similar amplitude of $\sim 1.2 \mathrm{~Sv}$, which is in much better agreement with the observations compared to Coarse_bclin_flat. All curves lie in the gray shaded area, which again marks the observations enveloped by the standard deviation. The background flow seems thus of minor importance for the seasonal cycle of the Florida Current. However, the phase seems somewhat shifted in the model runs compared to the observations, where the maximum is found in July. In Coarse_bclin, maximum values are found in late winter and a pronounced minimum shows up in October. In Coarse, maximum values are found in spring and the phase seems generally shifted by 1-2 months compared to Coarse_bclin. The main reason for this shift is baroclinic Rossby wave activity in the interior, which will be discussed later.

Anderson and Corry (1985b) found that the meridional component of the wind stress is responsible for the maximum in summer, which we also find. Figure 6 shows the annual cycle of the Florida Current calculated from adjoint sensitivities for both wind stress components in Coarse bclin. Using zonal wind stress only results in a winter maximum and appears related to the pronounced minimum in October. Here, contrary to Anderson and Corry (1985b), the amplitude of the zonal component is greater than in the meridional component, leading to the overall maximum in late winter (Fig. 5). Note that the differences between Anderson and Corry (1985b) and our results are mainly due to the chosen wind stress product (see discussion below). The seasonal cycle in the Florida Current transport of both components resemble to a large degree the seasonal cycle of the wind stress components of the sensitive regions north of Florida Strait as shown in Fig. 4.

Because most of the previous studies (Anderson and Corry 1985b; Greatbatch and Goulding 1989; etc.) rely on the wind stress climatology of Hellerman and Rosenstein (1983), we additionally diagnose the annual cycle using their climatology (not shown). Here, the Florida Current transport has a maximum in July and a larger amplitude, which is in agreement with the cited earlier studies. The annual cycle is less pronounced when using the NCEP climatology. 


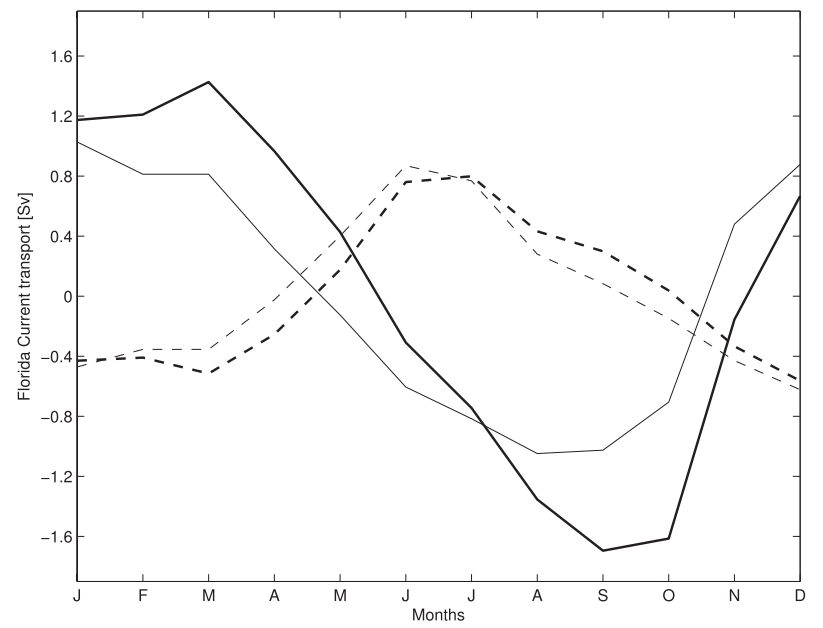

FIG. 6. Annual cycle of the Florida Current transport (Sv) derived from adjoint sensitivities to zonal wind stress (solid lines) and meridional wind stress (dashed lines). Results from two different model versions are shown. The baroclinic setup Coarse_bclin (thick lines) uses the sensitivities of the last $3 \mathrm{yr}$ prior cost function evaluation (as in Fig. 5). The barotropic setup Coarse_btrop (thin lines) uses only the sensitivities of the zeroth month.

\section{c. Impact of different wave types}

\section{1) BARotRopic WAVES}

The response of the Florida Current to wind forcing is the result of different types of waves, which will be now discussed in more detail. The most important ones on seasonal scales are barotropic waves. To separate the impact of initially barotropic waves and baroclinic waves, we set up the same model in a barotropic version without stratification but realistic topography (Coarse btrop). Figure 6 shows that large parts of the annual cycle are captured by a pure barotropic regime. This holds especially for the meridional component of the wind stress. The sensitivities of the Florida Current transport to wind stress within the month of cost function evaluation in Coarse_bclin are qualitatively comparable to Coarse btrop and follow the $f / H$ contours north of the Florida Strait (Fig. 7; only the sensitivity to the zonal wind stress component is shown). The barotropic wave response is fast and contributions from previous months are therefore at least one order of magnitude smaller in Coarse_btrop (Fig. 7e). The local dipole structure at $\sim 25^{\circ} \mathrm{N}, 77^{\circ} \mathrm{W}$ (e.g., in Fig. $7 \mathrm{~d}$ ) largely compensates when diagnosing the annual cycle as in Fig. 6 and leading to an amplitude of only $\sim 0.1 \mathrm{~Sv}$ in Coarse_btrop. Note that the barotropic wave response is the sum of barotropic topographic Rossby waves, barotropic continental shelf waves, Kelvin waves, and edge waves (Rhines 1970; Buchwald and Adams 1968). However, we do not attempt to decipher the different kinds of barotropic waves here.

\section{2) BAROCLINIC WAVES NEAR THE BOUNDARIES}

Comparing the baroclinic case Coarse_bclin (Figs. 7ac) and the barotropic case Coarse_btrop (Figs. 7d,e), obviously further types of waves are involved in the Florida Current variability in case of a stratified ocean. In case of sufficient stratification, continental shelf waves turn into baroclinic coastally trapped waves (e.g., Huthnance 1978). Furthermore, baroclinic topographic Rossby waves follow the $f / H$ contours. However, here, we do not distinguish between baroclinic coastally trapped waves and baroclinic topographic Rossby waves and call them combined baroclinic waves near the boundaries. Coupling between these baroclinic waves and the barotropic signal, which determines the Florida Current transport, is by means of the joint effect of baroclinicity and relief (JEBAR) (Sarkisyan and Ivanov 1971).

We assume that the differences between the barotropic and the baroclinic model along the shelf north of the Florida Strait can be attributed to baroclinic waves. Note that the sensitivities are much weaker 2 months before evaluation (Fig. 7c) and very weak outside the subtropical gyre in this model. If we integrate the differences in the sensitivities 3 months (zeroth to second month) before evaluation between Coarse_btrop and Coarse_bclin north of $28^{\circ} \mathrm{N}$ in order to capture the impact of these waves on the annual cycle of the Florida Current transport, the amplitude is only $\sim 0.1 \mathrm{~Sv}$ (not shown). This is partly due to the compensating dipole structure all along the shelf (Fig. 7b) and partly due to a compensation between meridional and zonal wind stress components. Therefore, baroclinic shelf waves cannot explain the differences in the sensitivities of the Florida Current transport between Coarse_btrop and Coarse_bclin to zonal winds (Fig. 6).

\section{3) BAROCLINIC WAVE ACTIVITY IN THE INTERIOR}

A further type of wave that contributes to Florida Current transport variability is the long baroclinic (planetary) Rossby wave. These waves are nondispersive with westward phase and group velocities. Rossby waves are perturbations around the mean potential vorticity gradient. The difference to the previously considered baroclinic waves along the shelf is that here mainly the planetary vorticity sets the mean potential vorticity gradient: that is, these waves reach the Florida Current from the interior. In the following, these long baroclinic planetary Rossby waves are referred as baroclinic Rossby waves. As mentioned in the introduction, these waves adjust the Sverdrup relation in their wake but their impact on seasonal time scales has traditionally been 



FIG. 7. Sensitivity of the Florida Current transport to zonal wind stresses (a) for the zeroth month during cost function evaluation and (b),(c) for both previous months in experiment Coarse_bclin. (d),(e) The results for the first two months in experiment Coarse_btrop. Units are $10^{-11} \mathrm{~Sv}\left(\mathrm{~N} \mathrm{~m}^{-2}\right)^{-1}$. (f) The $f / H$ contours $\left(10^{8} \mathrm{~s}^{-1} \mathrm{~m}^{-1}\right)$.

considered to be small because the basin crossing time is up to decades.

In Coarse_bclin, it can be seen that the baroclinic Rossby waves adjust the Sverdrup relation in their wake. The first 3 months before evaluation are shown in Figs. $7 \mathrm{a}-\mathrm{c}$. The dipole pattern, seen in the first month before evaluation at $25^{\circ} \mathrm{N}, 77^{\circ} \mathrm{W}$, moves progressively eastward as we go back in time. Going back 2 and $3 \mathrm{yr}$ in time (Figs. 8a,b, respectively), we see a strong indication that baroclinic Rossby waves are playing a role in this eastward movement with positive (negative) sensitivities north (south) of $25^{\circ} \mathrm{N}$ similar to the flat-bottom Sverdrup case (Fig. 2). A Hovmoeller diagram of the sensitivities at $30^{\circ} \mathrm{N}$ shows that the signal becomes slowly weaker back in time (Fig. 8e). The basin crossing time from $\sim 20^{\circ} \mathrm{W}$ to the western boundary is around 55 months, leading to a phase speed of $\sim 3.7 \mathrm{~cm} \mathrm{~s}^{-1}$. The phase speed is faster compared to the expectation from linear theory for first-mode long baroclinic Rossby waves $c_{\mathrm{ph}}=\beta L_{d}^{2}$ of $2.2 \mathrm{~cm} \mathrm{~s}^{-1}$. Here, the first-mode baroclinic Rossby radius $L_{d}$ is approximated as $L_{d}=\int_{h}^{0} N d z /(|f| \pi)$ following Chelton et al. (1998). To calculate $c_{\mathrm{ph}}$, we take the zonal average along $30^{\circ} \mathrm{N}$. Note that $c_{\mathrm{ph}}$ differs substantially and is about $1.4 \mathrm{~cm} \mathrm{~s}^{-1}$ over the MidAtlantic Ridge (MAR) and about $2.7 \mathrm{~cm} \mathrm{~s}^{-1}$ over deepest ocean, which is $5000 \mathrm{~m}$ in the model. Observed westward propagating signals show a similar discrepancy to linear theory (Chelton and Schlax 1996). Many explanations for this discrepancy have been put forward (e.g., Killworth and Blundell 2005). In Coarse_ bclin, it is clear that baroclinic Rossby waves are influenced by topographic variations, which apparently lead to the speed as of the first-mode Rossby waves.

On its way toward the west, the signal is apparently affected by the topographic features (Fig. 8e). East of the MAR at $\sim 45^{\circ} \mathrm{W}$, only small sensitivities are found. The MAR thus acts like a barrier for baroclinic Rossby waves from the eastern basin as found in previous modeling and observational studies (e.g., Herrmann and Krauss 1989; Osychny and Cornillon 2004). Wind 



FIG. 8. Sensitivity of the Florida Current transport to zonal wind stresses (a),(c) 2 and (b),(d) 3 yr before evaluation of the cost function. Results (a),(b),(e) from experiment Coarse_bclin and (c),(d),(f) from experiment Coarse with fully evolved circulation are shown. (e),(f) Hovmoeller diagrams showing the evolution of the sensitivity at $30^{\circ} \mathrm{N}$. The cost function is evaluated at month 60 . Units are $10^{-12} \mathrm{~Sv}$ $\left(\mathrm{N} \mathrm{m}^{-2}\right)^{-1}$.

forcing over the MAR could also generate baroclinic Rossby waves (Barnier 1988), and it is also possible that they are generated at the western shelf edge at $\sim 75^{\circ} \mathrm{W}$, where we find the highest sensitivities.

A slower mode needs 60 months from $\sim 60^{\circ} \mathrm{W}$ to reach the Florida Current. Note the nonuniform contour interval in Figs. 8e,f. Both Rossby modes could be also identified in the sensitivities to potential temperature (not shown). The vertical structure of the slower mode resembles that of the second baroclinic Rossby mode. The phase velocity of $1.1 \mathrm{~cm} \mathrm{~s}^{-1}$ is again faster than the prediction of linear theory, which is $0.68 \mathrm{~cm} \mathrm{~s}^{-1}$ over the deep ocean in the model.

In Coarse_bclin, only topographic features are able to modify the mean potential vorticity gradient in the eastwest direction. In Coarse including a background flow, the waves are also affected by the mean advection. Moreover, the characteristics will be changed by the horizontally nonuniform stratification. Figures $8 \mathrm{c}, \mathrm{d}$ show the sensitivity of the Florida Current to zonal wind stresses in Coarse. Compared to Coarse_bclin, the wave structures are more complicated but share some of the 


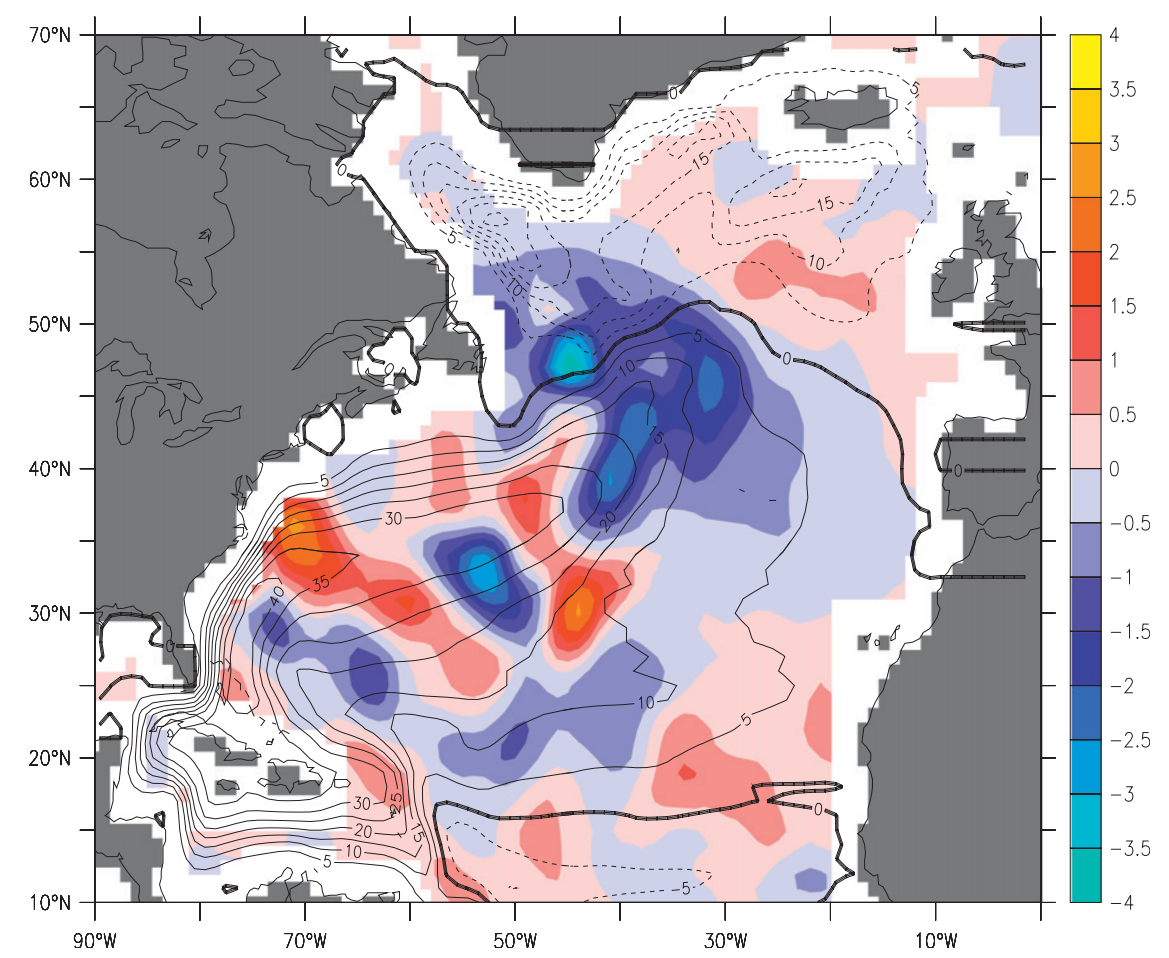

FIG. 9. Sensitivity of the Florida Current to potential temperatures at the bottom (deepest grid box) in experiment Coarse 4 yr before evaluation of the cost function. Sensitivities are normalized to a temperature anomaly applied over a volume of $1 \mathrm{~m}^{3}$ and smoothed by a running mean over three grid points in the horizontal. Units are $10^{-12} \mathrm{~Sv}\left(\mathrm{~K} \mathrm{~m}^{-3}\right)^{-1}$. Contour lines show the annual-mean horizontal streamfunction $(\mathrm{Sv})$ of the underlying mean state.

features of the model at rest. Both models show in general the sign change along $25^{\circ} \mathrm{N}$ in agreement with Sverdrup theory. A comparison using Hovmoeller diagrams at $30^{\circ} \mathrm{N}$ shows that both models contain similar modes, but in Coarse much more energy is contained in the second baroclinic mode, reaching $\sim 60^{\circ} \mathrm{W}$ after 60 months. The propagation of the second baroclinic mode is rather southwestward than purely westward as can be seen in the Rossby wave train in Figs. 8c,d, reaching from $\sim 35^{\circ} \mathrm{N}, 55^{\circ} \mathrm{W}$ to $\sim 25^{\circ} \mathrm{N}, 70^{\circ} \mathrm{W}$.

Figure 9 shows the sensitivity to potential temperatures at the bottom (i.e., in the lowermost grid box of Coarse). Additionally, the underlying mean circulation is shown in terms of the horizontal streamfunction. The source regions of the second-baroclinic-mode Rossby wave train are the Grand Banks, especially at Flemish Cap $\left(\sim 47^{\circ} \mathrm{N}, 46^{\circ} \mathrm{W}\right)$, and an area on the western side of the MAR between $\sim 36^{\circ}$ and $46^{\circ} \mathrm{N}$. In these regions, pronounced topographic features interact with strong mean currents such as the North Atlantic Current and the deep western boundary current. Note that in these source regions the sensitivities are bottom intensified (not shown). These signals then slowly move upward on their way toward the southwest suggesting a vertical component in the group velocity. The wave train approximately follows the return flow, which corresponds to the deep western boundary current in that model (Fig. 9). Such a clear southwesterly wave train of secondbaroclinic-mode structure is missing in Coarse_bclin (Figs. 8a,b), where a mean flow is not present. This also points toward an interaction of the mean flow with topography as forcing mechanism. The source region and propagation to the southwest are in some agreement with the observation of Osychny and Cornillon (2004), who suggest an interaction of the Gulf Stream and/or deep western boundary current with the bottom topography southeast of the Grand Banks as source for the waves. Note, however, that in contrast to our findings the signals in their study propagate faster with speeds above the theoretical values for the first baroclinic mode. Contrary to the previously discussed wave types, it is unlikely that the Rossby wave train of second baroclinic mode found in our model is excited by wind stress directly. However, the forcing determines the necessary variability in the western boundary currents, which then interact with the topography generating the waves.

In Coarse, maximum values in the Florida Current transport are found in late spring/early summer, which is 


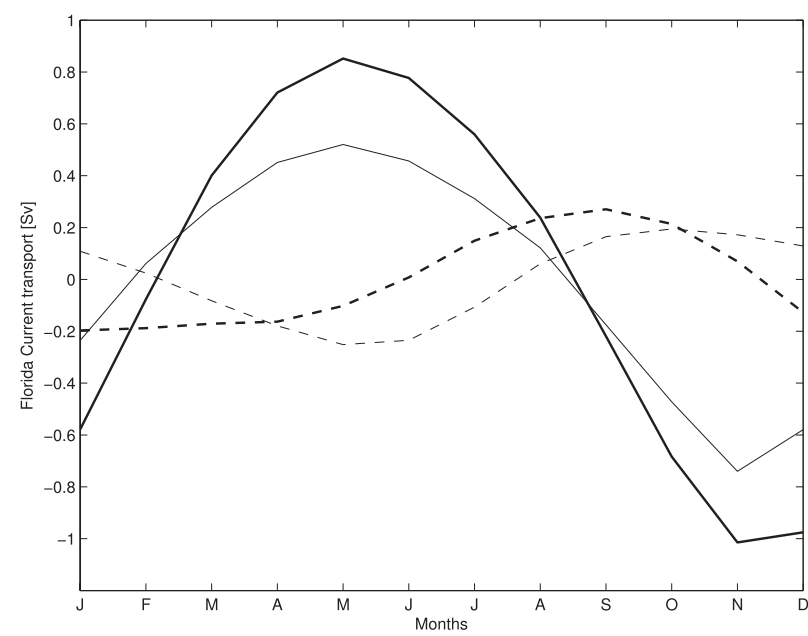

FIG. 10. Annual cycle of the Florida Current transport (Sv) derived from adjoint sensitivity to zonal wind stress (solid lines) and meridional wind stress (dashed lines). Results from experiment Coarse (thick lines) and from experiment Coarse_bclin (thin lines) are shown. To filter most of the barotropic waves, only the sensitivities of the last $3 \mathrm{yr}$ but without the zeroth month prior to cost function evaluation are considered.

somewhat later than in Coarse_bclin (Fig. 5). The main driver of the annual cycle (i.e., the waves) is qualitatively very similar in both experiments (not shown). The main differences between both experiments are due to missing southwesterly wave train in Coarse_bclin. Figure 10 shows the annual cycle diagnosed for both experiments and each wind stress component using the sensitivities of the last $3 \mathrm{yr}$ before evaluation. To filter out the common barotropic signal, the first month before evaluation is subtracted. The component of the Florida Current due to the meridional wind stress has an amplitude of only $0.2 \mathrm{~Sv}$ in both models with a slightly different phase. In agreement with flat-bottom Sverdrup theory, the zonal wind stress is the important component for the Florida Current transport. Maximum values are found in late spring/early summer, and minimum values occur during winter. The baroclinic Rossby waves in the interior partly compensate the barotropic signal (Fig. 6). The amplitude of $\sim 0.9 \mathrm{~Sv}$ is stronger in the Coarse with background circulation compared to the $\sim 0.5 \mathrm{~Sv}$ in Coarse_bclin, which leads to the overall maximum in late spring/early summer in Coarse (Fig. 5).

\section{d. Impact of model setup}

To investigate the impact of topographic details and mixing parameters we use a high-resolution version of our model (High_bclin) and compute the sensitivity of the Florida Current using a basic state at rest. Because higher resolution allows less viscosity, we expect the waves to be less damped. Figure 11 shows the sensitivities of the Florida Current transport to zonal and meridional wind stresses in the zeroth month during cost function evaluation. In contrast to the low-resolution case, distinct sensitivities are found also in the subpolar North Atlantic and even along the eastern boundary of the North Atlantic. Note that it is simply because of the geometry of the coastline that positive zonal and meridional wind stresses (and accompanying Ekman transports) have the same sign in the sensitivities in the subtropics and opposite signs in most parts of the subpolar region. Because the zonal (meridional) wind stress has its maximum in winter (summer), sensitivities of both components in the subpolar gyre contribute to a summer maximum in the annual cycle of the Florida Current transport. The sensitivity pattern in High_bclin are much narrower compared to the low-resolution cases.

Contrary to the low-resolution model, the Florida Strait in High_bclin is a proper channel, with an eastern side bounded by islands or shallow water. This allows signal propagation from the south of the Florida Strait, as seen by the higher sensitivities around Cuba.

Figure 12 shows the diagnosed annual cycle in Fig. 5 but for High_bclin using again the NCEP climatology. Because of the sensitivities in the subpolar North Atlantic, the Florida Current has a pronounced maximum in summer and an amplitude of $\sim 1.6 \mathrm{~Sv}$. For comparison, we diagnosed the annual cycle by considering only the sensitivities of the subtropical gyre. The resulting annual cycle is indeed qualitatively similar to Coarse bclin (Fig. 5), although the amplitude is stronger. The main reason might be the less viscous damping again.

The lateral viscosity in the high-resolution model is biharmonic using a value of $3 \times 10^{10} \mathrm{~m}^{4} \mathrm{~s}^{-1}$, whereas in the low-resolution model we usually apply a harmonic coefficient of $1 \times 10^{4} \mathrm{~m}^{2} \mathrm{~s}^{-1}$. Because our model is at rest, we are able to run the adjoint model using the viscosity of the high resolution in our low-resolution model; however, the sensitivities in the subpolar gyre are still very low (not shown). However, if additionally the C-D scheme (Adcroft et al. 1999) is switched off, comparable results between both resolutions could be achieved (Fig. 12). Note that in the low viscous run without the $\mathrm{C}-\mathrm{D}$ scheme a lot of grid noise persists. However, the results indicate that our outcomes are not sensitive to a better representation of topographic features but to viscous damping.

\section{Summary and discussion}

We have used an adjoint model to investigate the mechanisms responsible for the annual cycle of the Florida Current transport. The adjoint approach successfully identifies the key regions for the forcing in 

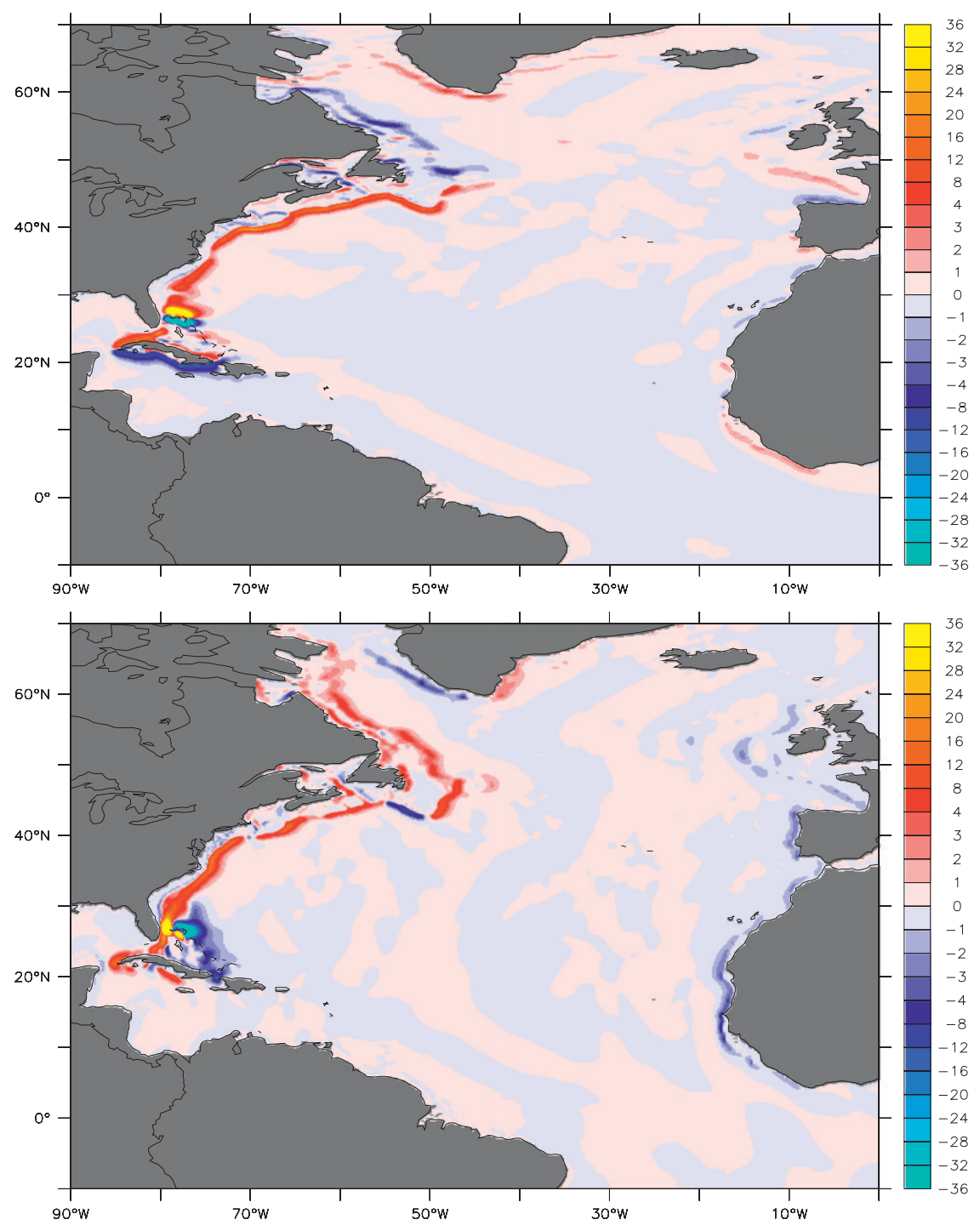

FIG. 11. Sensitivity of the Florida Current transport to (top) zonal and (bottom) meridional wind stress from the zeroth month within the cost function evaluation of the high-resolution experiment High_bclin. Units are $10^{-11} \mathrm{~Sv}\left(\mathrm{~N} \mathrm{~m}^{-2}\right)^{-1}$.

a systematic and physically consistent manner. This approach allows for the first time a quantitative estimate of the relative contributions of different wave types and forcing regions. Although the Florida Current is also a pathway of the global overturning circulation, our results suggest that the annual cycle is driven by wind forcing and that thermohaline forcing plays no role. The linear adjoint approach successfully reproduces the Florida Current variability on seasonal time scales in agreement with flat-bottom Sverdrup theory. The adjoint approach also successfully reproduces the variability of a full nonlinear model in the case of variable bottom topography with realistic (observed) amplitudes of $\sim 1.2 \mathrm{~Sv}$.
The main findings of the study are as follows:

- By far the largest contribution for the annual cycle comes from barotropic waves generated by wind stress anomalies north of the Florida Strait along the shelf off the North American coast. These wind stress anomalies induce anomalies in the coastal upwelling (downwelling). Fast barotropic waves propagate these signals southward. They reach the Florida Strait within 1 month and cause an annual cycle with an amplitude of $\sim 1 \mathrm{~Sv}$.

- There is a considerable contribution due to long baroclinic planetary Rossby waves generated by anomalous wind stress curl forcing in the interior. Annual cycles caused by these waves reach amplitudes of 




FIG. 12. Annual cycle of the Florida Current transport (Sv) derived from adjoint sensitivities to wind stress in experiment High_bclin using all sensitivities (solid thick line) and using only sensitivities in the subtropical gyre (solid thin line) and in experiment Coarse_bclin but with low viscosity and without C-D scheme (dashed line). In all cases, the sensitivities of the last 3 months (zeroth to second month) prior to cost function evaluation are considered. For comparison, the gray shaded area marks the variability of the observations as in Fig. 1.

$\sim 0.8 \mathrm{~Sv}$ but have different phases (i.e., the amplitudes do not add up constructively). First-mode baroclinic Rossby waves propagate from the interior westward to the Florida Strait, adjusting the Sverdrup relation in their wake. The magnitude of the corresponding sensitivity is highly influenced by topography. The highest sensitivities are found at the western shelf edge. Considerable sensitivities extend toward the east to the MAR, which acts as a barrier, whereas sensitivities east of the MAR are very low.

- Second-mode baroclinic Rossby waves have also an impact on the Florida Current variability. A wave train originates from northeast where the North Atlantic Current and deep western boundary current interact with bottom topography at the Grand Banks (Flemish Cap) and at the MAR between $\sim 36^{\circ}$ and $46^{\circ} \mathrm{N}$. Contrary to all other discussed wave types, it is unlikely that this wave response is excited by wind stress directly but rather through forced variability in the western boundary currents.

- The impact of local wind stress forcing within the Florida Strait is rather weak. The local response shows up as a dipole structure in the sensitivities to both wind stress components and hence depends crucially on the local wind stress curl. In the NCEP climatology, this local forcing causes an amplitude of only $\sim 0.1 \mathrm{~Sv}$.

- Baroclinic waves along the continental shelf are also of minor importance for the annual cycle of the Florida
Current. A comparison between a barotropic and a baroclinic model version reveals that these waves mainly originate north of the Florida Strait along the shelf off the North American coast, reaching the Florida Strait within 3 months. However, an annual cycle caused by baroclinic shelf waves alone has an amplitude of only $\sim 0.1 \mathrm{~Sv}$.

- A high-resolution model version reveals that the exact representation of the topography and land/sea mask is of minor importance for the annual cycle. However, higher resolution allows for less viscous damping of the waves: for example, barotropic waves from more remote shelf regions (e.g., Labrador Sea) contribute to the annual cycle as well.

The total variance of Florida Current transport variability on intraannual to interannual time scales exceeds the variance at annual time scales (Atkinson et al. 2010). Meinen et al. (2010) suggest that at least $25 \mathrm{yr}$ of observations are needed to achieve a mean annual cycle with an accuracy of $0.2 \mathrm{~Sv}$. We have shown that climatological wind stress forces an annual cycle through a sequence of linear waves. Nevertheless, an exact match between the observed and modeled annual cycles is likely to be difficult to obtain. One reason is the observational uncertainty in the observed seasonal cycle (for the reasons given above), and the other is the uncertainty in the wind stress climatologies available for driving a model. For example, using the climatology of Hellerman and Rosenstein (1983), instead of NCEPNCAR, increases the amplitude of the modeled seasonal cycle from 1.2 to $2.0 \mathrm{~Sv}$ when the sensitivities from Coarse bclin are used.

The highest sensitivities to wind stress forcing in each of our experiments are found locally within the Florida Strait. However, the pattern shows up always as a dipole of negative/positive sensitivities, which compensate each other when applied to a large-scale wind stress pattern as in the NCEP-NCAR climatology. The local forcing would become important if the forcing would show a strong local wind stress curl. Schott et al. (1988) suggest an important role of the local forcing based on statistical correlations with local winds. However, note that such a correlation could be overstated because the local meridional wind stress is highly correlated with along-coast winds to the north.

Long first-mode baroclinic Rossby waves from the interior are important for the annual cycle. The phase shift in the sensitivity to the zonal wind stress between the barotropic (Fig. 6) and baroclinic response (Fig. 8) can be explained by the time baroclinic Rossby waves need to travel from distinct topographic features to reach and influence the Florida Current. Barnier (1988) 
points toward the impact of the MAR on wind-forced baroclinic Rossby waves. The adjoint sensitivities suggest that the western shelf edge seems to be an even more important source region in our case because the sensitivities are much higher here. We also found an impact of the second baroclinic mode on the annual cycle. This mode only becomes important when a mean flow is present. The source region and the fact that considerable sensitivities show up only when a mean flow is present suggest that it is caused by an interaction between topography and the Gulf Stream and/or deep western boundary current, in some agreement to previous studies (Herrmann and Krauss 1989; Osychny and Cornillon 2004). This would lead to a positive feedback mechanism for internal Florida Current/Gulf Stream variability not driven by wind stress directly.

The Rossby wave phase velocities of the first two baroclinic modes deduced from the adjoint sensitivities are significantly faster than the prediction from linear theory. A similar discrepancy is also found in satellite observation (Chelton and Schlax 1996). However, the mean circulation as suggested by Killworth and Blundell (2005) seems not responsible for this discrepancy. The phase velocities in our experiments including a mean circulation Coarse are very similar to those in Coarse bclin without a mean circulation. Note that in Coarse bclin only topographic variations change the flat-bottom Rossby wave speed.

The impact of the Bahamas and the gaps between them on the transmission of baroclinic Rossby waves is not fully understood yet. Our low-resolution model cannot be used to address this question because the Bahamas are not adequately resolved. The high-resolution adjoint model could not be used in this respect as it can only be integrated 3 months back in time. It seems obvious that the waves are being modified by the Bahamas. However, more idealized studies support the idea that a substantial part of the energy might slip through the gaps (Pedlosky and Spall 1999; Pedlosky 2000; Simmons and Nof 2002). Some observational evidence is given by DiNezio et al. (2009), who found a correlation between Florida Current transport variability and interior wind stress curls on longer than annual time scales. It is also observed that the variability in the major gaps (e.g., in the northwest Providence Channel) contributes to the Florida Current transport variability as measured by the cable data (Hamilton et al. 2005).

The strong intraannual to interannual variability of the Florida Current results from internal ocean variability driven by mesoscale eddies (Lin et al. 2010; Mildner et al. 2011, manuscript submitted to Geophys. Res. Lett.). Both studies show a clear relationship between eddy shedding of the Loop Current in the Gulf of
Mexico and minima in the Florida Current transport based on observations and models. Note that our adjoint sensitivity studies cannot capture such an effect.

Note, however, that most of the Florida Current transport variability occurs on scales shorter than the annual signal, which accounts for only $\sim 10 \%$ of the variance of the Florida Current, whereas interannual and longer periods represent $\sim 23 \%$ (Meinen et al. 2010). Further adjoint sensitivity studies offer one route to unraveling and attributing the contributions to Florida Current variability on different time scales. Czeschel et al. (2010) have shown, using the meridional overturning circulation as cost function, that adjoint backward calculations are applicable on time scales up to 15-20 yr in such model configurations.

Acknowledgments. The model integrations have been performed on a NEC-SX8 at the computing center at the University Kiel, Germany, and on an IBM Power6 at the Deutsches Klimarechenzentrum (DKRZ), Hamburg, Germany. The Florida Current cable and section data are made freely available on the Atlantic Oceanographic and Meteorological Laboratory webpage (http://www.aoml. noaa.gov/phod/floridacurrent/) and are funded by the NOAA Office of Climate Observations. LC and RJG acknowledge support from IFM-GEOMAR.

\section{REFERENCES}

Adcroft, A. J., C. N. Hill, and J. C. Marshall, 1999: A new treatment of the Coriolis terms in C-grid models at both high and low resolutions. Mon. Wea. Rev., 127, 1928-1936.

Anderson, D. L. T., and P. D. Killworth, 1977: Spin-up of a stratified ocean, with topography. Deep-Sea Res., 24, 709-732.

_ wind forcing with application to the seasonal variation in the Florida Straits-Gulf Stream transport. Prog. Oceanogr., 14, 740 .

$\longrightarrow$, and 1985b: Seasonal transport variations in the Florida Straits: A model study. J. Phys. Oceanogr., 15, 773-786.

Atkinson, C. P., H. L. Bryden, J. J.-M. Hirschi, and T. Kanzow, 2010: On the seasonal cycles and variability of Florida Straits, Ekman and Sverdrup transports at $26^{\circ} \mathrm{N}$ in the Atlantic Ocean. Ocean Sci., 6, 837-859, doi:10.5194/os-6-837-2010.

Baringer, M. O. N., and J. Larsen, 2001: Sixteen years of Florida Current transport at $27^{\circ}$ N. Geophys. Res. Lett., 28, 3179-3182.

Barnier, B., 1988: A numerical study on the influence of the MidAtlantic Ridge on nonlinear first-mode baroclinic Rossby waves generated by seasonal winds. J. Phys. Oceanogr., 18, 417-433.

_ L. Liefridt, and P. Marchesiello, 1995: Thermal forcing for a global ocean circulation model using a three-year climatology of ECMWF analyses. J. Mar. Syst., 6, 363-380.

Böning, C. W., R. Döscher, and R. G. Budich, 1991: Seasonal transport variation in the western subtropical North Atlantic: Experiments with an eddy-resolving model. J. Phys. Oceanogr., 21, 1271-1289. 
Bryden, H. L., W. E. Johns, and P. M. Saunders, 2005: Deep western boundary current east of Abaco: Mean structure and transport. J. Mar. Res., 63, 35-57.

Buchwald, V. T., and J. K. Adams, 1968: The propagation of continental shelf waves. Proc. Roy. Soc. London, 305A, 235 250.

Chelton, D. B., and M. G. Schlax, 1996: Global observations of oceanic Rossby waves. Science, 272, 234-238.

—, R. A. deSzoeke, M. G. Schlax, K. El Naggar, and N. Siwertz, 1998: Geographical variability of the first baroclinic Rossby radius of deformation. J. Phys. Oceanogr., 28, 433-460.

Czeschel, L., D. P. Marshall, and H. L. Johnson, 2010: Oscillatory sensitivity of Atlantic overturning to high-latitude forcing. Geophys. Res. Lett., 37, L10601, doi:10.1029/2010GL043177.

DiNezio, P. N., L. J. Gramer, W. E. Johns, C. S. Meinen, and M. O. Baringer, 2009: Observed interannual variability of the Florida Current: Wind forcing and the North Atlantic Oscillation. J. Phys. Oceanogr., 39, 721-736.

Giering, R., and T. Kaminski, 2003: Applying TAF to generate efficient derivative code of Fortran 77-95 programs. Proc. Appl. Math. Mech., 2, 54-57.

Gill, A. E., and P. P. Niller, 1973: The theory of the seasonal variability in the ocean. Deep-Sea Res. Oceanogr. Abstr., 20,141177.

Greatbatch, R. J., and A. Goulding, 1989: Seasonal variations in a linear barotropic model of the North Atlantic driven by the Hellerman and Rosenstein wind stress field. J. Phys. Oceanogr., 19, 572-595.

_ L. L. Youyu, B. DeYoung, and J. C. Larsen, 1995: The variation of transport through the Straits of Florida: A barotropic model study. J. Phys. Oceanogr., 25, 2726-2740.

Hamilton, P., J. Larsen, K. Leaman, T. Lee, and E. Waddell, 2005: Transports through the Straits of Florida. J. Phys. Oceanogr., 35, 308-322.

Hellerman, S., and M. Rosenstein, 1983: Normal monthly wind stress over The World Ocean with error estimates. J. Phys. Oceanogr., 13, 1093-1104.

Herrmann, P., and W. Krauss, 1989: Generation and propagation of annual Rossby waves in the North Atlantic. J. Phys. Oceanogr., 19, 727-744.

Huthnance, J. M., 1978: On coastal trapped waves: Analysis and numerical calculation by inverse iteration. J. Phys. Oceanogr., 8, 74-92.

Johns, W., L. Beal, M. Baringer, J. Molina, S. Cunningham, T. Kanzow, and D. Rayner, 2008: Variability of shallow and deep western boundary currents off the Bahamas during 2004 05: Results from the $26^{\circ} \mathrm{N}$ RAPID-MOC array. J. Phys. Oceanogr., 38, 605-623.

Kalnay, E., and Coauthors, 1996: The NCEP/NCAR 40-Year Reanalysis Project. Bull. Amer. Meteor. Soc., 77, 437-471.

Killworth, P., and J. Blundell, 2005: The dispersion relation for planetary waves in the presence of mean flow and topography.
Part II: Two-dimensional examples and global results. J. Phys. Oceanogr., 35, 2110-2133.

Köhl, A., and J. Willebrand, 2002: An adjoint method for the assimilation of statistical characteristics into eddy-resolving ocean models. Tellus, 54A, 406-425.

Larsen, J. C., 1992: Transport and heat flux of the Florida Current at $27^{\circ} \mathrm{N}$ derived from cross-stream voltages and profiling data: Theory and observations. Philos. Trans. Roy. Soc., 338A, 169236.

Lee, T., W. Johns, R. Zantopp, and E. Fillenbaum, 1996: Moored observations of western boundary current variability and thermohaline circulation at $26.5^{\circ} \mathrm{N}$ in the subtropical North Atlantic. J. Phys. Oceanogr., 26, 962-983.

Levitus, S., and T. P. Boyer, 1994: Temperature. Vol. 4, World Ocean Atlas 1994, NOAA Atlas NESDIS 4, 117 pp.

Lin, Y., R. J. Greatbatch, and J. Sheng, 2010: The influence of Gulf of Mexico Loop Current intrusion on the transport of the Florida Current. Ocean Dyn., 60, 1075-1084.

Marotzke, J., R. Giering, K. Q. Zhang, D. Stammer, C. Hill, and T. Lee, 1999: Construction of the adjoint MIT ocean general circulation model and application to Atlantic heat transport sensitivity. J. Geophys. Res., 104 (C12), 29 529-29 547.

Marshall, J. C., C. N. Hill, L. Perelman, and A. J. Adcroft, 1997: Hydrostatic, quasi-hydrostatic, and nonhydrostatic ocean modeling. J. Geophys. Res., 102 (C3), 5733-5752.

Meinen, C. S., M. O. Baringer, and R. F. Garcia, 2010: Florida Current transport variability: An analysis of annual and longerperiod signals. Deep-Sea Res. I, 57 (7), 835-846.

Niiler, P. P., and W. S. Richardson, 1973: Seasonal variability of the Florida Current. J. Mar. Res., 31, 144-167.

Osychny, V., and P. Cornillon, 2004: Properties of Rossby waves in the North Atlantic estimated from satellite data. J. Phys. Oceanogr., 34, 61-76.

Pedlosky, J., 2000: The transmission of Rossby waves through basin barriers. J. Phys. Oceanogr., 30, 3077-3101.

_ barriers. J. Phys. Oceanogr., 29, 2332-2349.

Rhines, P., 1970: Edge-, bottom-, and Rossby waves in a rotating stratified fluid. Geophys. Astrophys. Fluid Dyn., 1, 273-302.

Sarkisyan, A. S., and V. F. Ivanov, 1971: Joint effect of baroclinicity and bottom relief as an important factor in the dynamics of sea currents. Izv. Akad. Nauk SSSR, Fiz. Atmos. Okeana, 7, 173-188.

Schmitz, W. J., Jr., and P. L. Richardson, 1991: On the sources of the Florida Current. Deep-Sea Res., 38, S379-S409.

— J. D. Thompson, and J. R. Luyten, 1992: The Sverdrup circulation for the Atlantic along $24^{\circ}$ N. J. Geophys. Res., 97 (C5), $7251-7256$.

Schott, F. A., T. N. Lee, and R. Zantopp, 1988: Variability of structure and transport of the Florida Current in the period range of days to seasonal. J. Phys. Oceanogr., 18, 1209-1230.

Simmons, H., and D. Nof, 2002: The squeezing of eddies through gaps. J. Phys. Oceanogr., 32, 314-335. 